\title{
Measuring Interpersonal and Institutional Trust in the Context of a Democratic Educational Policy in Campinas City, Brazil
}

\author{
Sara Badra de Oliveira, Dirceu da Silva, Mara Regina Lemes De Sordi \\ UNICAMP, Brazil
}

\begin{abstract}
Since the 1980 trust has been conceived as a relational or organizational resource that leads to 'organizational effectiveness' and 'orientation towards innovation' through strengthening cooperation in the school-level. We sought to investigate how this concept is shaped in the context of a Brazilian municipal education system where a Participatory Institutional Evaluation policy is taking place. Considering trust as a result of social relations pervaded by respect, personal regard, recognition, integrity, competence and support, a Likert Trust Scale was built embracing the following relational settings: teachers - teachers; teachers management team; teachers - parents; teachers Municipal Department of Education. It was applied to 559 teachers from thirty municipal schools and submitted to face, content and statistical validation. We show the final structure of the Scale with the retained items which met very satisfactorily the criteria of statistical validity. We discuss the findings in the light of quantitative and qualitative data brought from field ethnography coupled with theoretical reflections motivated by the theories of recognition and communicative action. It allows us to acknowledge the shortcomings of the existing theories on trust in schools, pointing to the need for future investigations to pay closer attention to the way interpersonal and institutional trust is attached to the aims of social justice and enables the collective construction of negotiated social goals for education. By doing so, trust can be a valuable asset for democratic modes of regulation to flourish as an alternative to vertical accountability reforms.
\end{abstract}

\section{Introduction}

Since the 1980s theories have been drawing attention to the quality of social exchanges between teachers and their colleagues, parents and the school's principal - and the extent to which they are bound together by a shared vision, shared responsibilities, and common expectations - pointing to the role it plays in determining the failure/success of educational reforms. Among these social exchanges, theories specifically highlight "trust" as an important relational resource, or a property of school organizations, producing consequences for both the effectiveness of the school and its capacity to engage in collective improving efforts focused on academic learning, especially in terms of achieving better proficiency outcomes.

These theories stem from two main frameworks. The first started in the 1980s at Rutgers University and then, after a brief break, continued first at The Ohio State University and then at Oklahoma State University and the University of Oklahoma [1] [2] [3] [4]. It seems to be led by Wayne K. Hoy. The second systematic study of trust in schools started in the early 2000 by researchers at the University of Chicago such as Anthony Bryk and Barbara Schneider [5]. In its turn these theories draw inspiration especially on Talcott Parsons' sociological theory of system effectiveness and on James Coleman's and Robert Putnam's theories of social action and social capital.

Despite their differences ${ }^{\mathrm{i}}$, in general these two frameworks are grounded on the assumption that interdependency and vulnerability are conditions for and require the emergence of trust. Without trust, the social interactions among vulnerable and interdependent groups, individuals and institutions become fragmented leading to the dilution of social action.

School settings provide a specific environment for such analysis as they are inherently characterized by interdependence among people and role groups that need to rely upon one another and cooperate in order to achieve their common interests regarding students learning. These highly interdependent groups are consequently vulnerable to each other which entails certain level of risk and unpredictability, thereby establishing the need for high levels of collective trust. For example, teachers are vulnerable to parents 
because they depend on parent support regarding for instance monitoring students' attendance and homework; parents in turn are vulnerable to teachers on whom they depend for their children's development.

Both behaviours mentioned above are difficult to predict. Then in order to decide whether to trust in the other, the trustor group needs to resort to a "cognitive evaluation" or a "careful calculation" of the behavioural history, reputation or credentials of the trustee group, based on their personal experiences and especially on the shared perceptions about the trustworthiness of the trustee that emerge over time out of multiple social exchanges within the trustor group. Throughout these exchanges, people inside this group share with each other their expectations for appropriate behaviour by members of the other group - expressed in terms of openness, honesty, benevolence, reliability and competence and compare such expectations to observed behaviour of members of the other group, resulting in an emergent consensus about the trustworthiness of this other group [1].

Wayne Hoy's framework uses the Faculty as the trustor group to analyse how trust is built among three relational sets: faculty-faculty; faculty-clients (students and parents) and faculty-principal. They define Collective Trust as

'an individual's or group's willingness to be vulnerable to another party based on the confidence that the later party is benevolent, reliable, competent, honest, and open'[2]

Openness is defined as synonymous of transparency (the extent to which relevant information is shared or actions and plans are transparent); honesty is the expectancy that the word, promise, verbal or written statement of another individual or group can be relied upon; competence is the capacity to fulfil expectations; reliability is the extent to which one can rely upon another for action and goodwill; and benevolence is the confidence that the trusted person or group will protect one's interests.

Bryk and Schneider [5] also argue that the formation of trust depends on judgments about the extent to which observed actions, intentions and behaviours meet expectations. In other words - and also using teachers as the trustor -, trust of teachers in teachers, parents, and the principal increases as teachers, parents, and the principal act according to what teachers expect of them. These expectations are rooted in each role's obligations, but to meet expectations does not only require that the trustee individuals fulfil their role's obligations; it is also important how and why others go about the process of fulfilling their obligations. According to the authors, teachers analyze the behaviour of others through four lenses: personal regard (perception of how others care about them and are willing to extend themselves beyond what their role might formally require); competence (in the execution of individual's formal role responsibilities; instrumental concerns about ability to achieve desired outcomes); integrity (beyond consistency between what others say and do, someone has integrity if demonstrates commitment with children and with the shared purposes of the school); respect (how conversation takes place within a school community; a genuine sense of listening to what each person has to say).

The general argument in both frameworks is that relationships pervaded by trust tend to shape particular behaviors, willingness and climates in the school level - such as orientation towards innovation, engagement in problem-solving strategies, development of professional learning communities, strengthening of teamwork and cooperative relationships - which lead to students' achievement and "school effectiveness" (in terms of accommodation to environment and adaptability to changes [1]).

The aim of the researches is to achieve schoollevel performance through social action, defined as an emergent consequence of interdependent actions of actors and groups whose result is more than just a sum of individual behaviors. Trust is the glue that enables such exchanges and connections between people within groups and among all groups of a system to be converted into a social resource called "social capital", which allows the emergence of cohesion, reciprocity, collective beliefs and motivations and shared norms that support individual and group actions. Hence the achievement of effective school-level performance requires the formation of a cohesive social structure which hinges on "collective trust" or "relational trust" to connect people and groups to common visions around schooling.

These claims have clear implications for policy makers. The two theoretical frameworks are based on the assumption that people and relationships, not policies or interventions, reform and improve schools. The extent to which external partnerships and policy guidelines can be diffused within schools and result in effective change depends on the internal connections and the degree of social cohesion within the school itself. Hence instead of relying on practices of control over teachers, education policy needs to offer support for conditions that enable human and social capacity to flourish.

'Performance and innovation are jeopardized by a culture of control and enhanced by a culture of 
collective trust. Whereas control was a dominant policy model of the past, support needs to be the policy framework of the future. In short, our guidelines suggest a different route to school reform and improvement, one that goes through collective trust' [1].

This argument is especially strong as it challenges the prevailing notion that improvement and reform result from pressure, punitive consequences, and external accountability [1].

These features are accounted to be manifestations of the managerial culture of target setting and performance monitoring which characterizes the growing Global Educational Reform Movement [6]. It has been reported in many countries that this kind of "remedy" is not being able to support educational improvement in terms of proficiency outcomes not to mention that it is causing negatives consequences for the achievement of valuable goals such as social justice [7] [8] [9].

In the attempt to offer an alternative to this political scenario, the city of Campinas (São Paulo Brazil) in 2008 decided to implement a Participatory Institutional Evaluation Policy (AIP - Avaliação Institucional Participativa) in all forty-four elementary schools of the municipal educational system. This policy is as a bottom-up mode of regulation, aimed at empowering local school members to collectively evaluate educational quality of their school. To evaluate in this sense is more than measuring or verifying a specific result; is to encourage a steady and collective reflection that recovers the connections between processes and results, conditions and outcomes, aiming at achieving negotiated goals.

The evaluative scheme involved the creation of an Evaluation Committee (CPA - Comissão Própria de Avaliação) within each school to ensure the participation of students, teachers, operational staff and families through the mediation of a pedagogical advisor representing the management team of the school. It also involved the promotion of meetings among CPAs and between CPAs and representatives of the Municipal Education Department in which CPA members could discuss their demands with the public authority, reflecting the fact that this alternative mode is grounded on the principles of shared accountability, social quality, multi-actor and multi-instance negotiation, and empowerment of local school subjects [10].

In the CPAs, participants are encouraged to discuss crucial issues such as 'what schools are for'. This type of debate about the values, purposes, content and organization of schooling is being less and less encouraged in schools by the advocates of neutrality, objectivity and efficiency. However, the
Participatory Institutional Evaluation Policy is committed to the inalienable right of students to have access to an educational project that goes beyond what tests measure, and therefore advocates a revival of the value debate around the educational content and the ends of public schooling.

Having such discussions as a guideline, the policy establishes that the CPA participants shall build a negotiated quality 'deal', deliberating goals to be achieved by the school, actions to be undertaken for this purpose, who is responsible for what and what indicators will best facilitate the monitoring of actions, all of which embodied in the school's Political Pedagogical Project.

This negotiated deal entails the development of deep and brave dialogues amongst people who share a commitment to building, through a confrontation among their different points of view, more accurate understandings towards a collective vision guided by the pursuit of a common interest. In order to do so, they need to recognise and respect initially different points of view moving on to a new stance now coloured by the multiple perspectives. Thus, it is through honest confrontation of positions that the school collective may find consensus - always subject to change - regarding the priority problems, necessary interventions and how the respective roles and responsibilities for delivering them will be distributed between itself and the public authority. It is, as Campos states [11], an "organized collective" for the "production of quality".

This type of school-level autonomy does not mean, however, isolation. Even recognizing that the leadership belongs to school actors, AIP does not ignore the richness of the external point of view which adds new ingredients and flavours to the process of institutional self-knowledge. The public authority also participates in the negotiation process, and the large-scale evaluation data are considered by the school community as an important indicator; however, they are sensitively used, placed in perspective in the light of other collectively negotiated quality indicators and in the light of the social contexts and objective conditions in which they are produced.

After this brief explanation, it must be clear that the principles and aims of the Participatory Institutional Evaluation Policy hold noticeable similarities with the concerns voiced by the previous theories on trust. The Brazilian policy also emphasizes the school as the target level in which social action, characterized by collective beliefs and shared responsibilities, can flourish in order to achieve desired educational outcomes.

Since the implementation of the policy, researchers of the State University of Campinas have 
been studying which factors contribute to strengthen or to hinder the success of this local democratic initiative. This context motivated the interest in investigating how the concept of Trust can be useful to understand this Brazilian reality, especially considering that so far any systematic research specifically focused on this topic has been undertaken in Brazil.

How "trust" can be a valuable asset for schools intending to work under the principles of Participatory Institutional Evaluation? Does "trust" help to explain the contradictions, shortcomings and strengths that have emerged throughout the implementation process of this democratic mode of evaluation and regulation? Inspired by the existing literature, our hypothesis is that this concept can add valuable contributions to the advocacy of participation and bottom-up accountability as an alternative to top-down accountability stemming from managerial control policies.

However, despite offering valuable contributions, the literature on trust fails to take account of three crucial aspects raised by the Participatory Institutional Evaluation (AIP) principles and that we categorize as following:

1. The public authority plays a crucial role in the education provision affecting a great deal the extent to which school actors are able to fulfil their responsibilities. Although mentioned, this aspect has been sidelined by the existing theories;

2. Education has other purposes beyond achieving narrow goals of proficiency in language and maths or "organizational effectiveness" in terms of "accepting" and "adjusting" to changes or "accommodating" to environment. Actually the AIP advocates that the purpose of the bottom-up collective evaluation is to negotiate a broader conception of educational quality better aligned with the aims of social justice and with the building of more humane relationships and conditions both within and outside schools. Hence the purpose of school cannot be limited to "adapting" to what is defined from the outside, especially when the current top-down policies induce the compliance with a narrow and utilitarian concept of quality, which is useful from a "purely economic point of view" [12];

3 . In this sense, the process of building collective beliefs and motivations is inherently pervaded by negotiation and conflict, whereby people from diverse and unequal backgrounds encounter each other, dialogue and expect to have their needs, capacities and voices recognized. This nature of collective work seems to be overlooked by the literature on trust, which seems to conceive social action as a collective affiliation to pre-established educational goals. Following the path of the functionalistic theory of society, social actors do not seem to be endowed with the power to produce and transform the social system. As a result, there is no space for accounts of how inequality and diversity pervade the production of shared values or common visions through mechanism of "negotiation" and "communicative action" [13] [14]. Actually the existing literature on Trust in schools states that social differences undermine trust and hence the emergence of collective beliefs which are more likely to develop inside homogeneous settings ${ }^{\mathrm{ii}}$. Even though they recognize that 'the external context [economic and minority status] of schools can present challenges to developing cohesive relationships, but as long as internal conditions support cooperative and interdependent transactions among school members, collective trust can exist' [1], they do not go further trying to understand the negotiated nature embedded in the formation of shared values. As a result, among others, any of the scales built by these researchers - measuring either trust or the associated conditions such as reflective dialogue, supportive climate, peer collaboration etc. comprises items regarding the collective construction of negotiated aims and conditions of schooling.

Bearing in mind these shortcomings and contributions of the existing theories, this current research sought to analyze how trust is built in the context of a Participatory Institutional Evaluation policy. In order to achieve that, we built a Trust Scale, the first validated in Brazil, which allowed us to measure the different levels of trust distributed along the following relational settings: teachers teachers; teachers - management team; teachers parents; teachers - Municipal Department of Education. Because "shared responsibility" is a corner stone of that Brazilian reality we decided to include a fourth relation (teachers - Department of Education) not considered by the previous works [1] [2] [3] [4] [5] .

The Scale's validation also allowed us to confirm that the four dimensions integrity, respect, personal regard and competence characterize the development of trust in all the four relational settings. To come to this conclusion we first sketched out a preliminary version of the items drawing inspiration on the existing measures but also based on some field research. Semi-structured interviews were conducted with thirty teachers from nine municipal schools who were asked: 'what do you expect of (teachers, parents, etc.)?' and 'what does the development of trust in (teachers, parents, etc.) depend on?'.

The 'content analysis' [15] of the interviews coupled with a comparison among items from the two explained theoretical frameworks showed that the four dimensions mentioned above were able to 
encompass both our categories drawn from the interviews and the categories of Wayne Hoy's tradition, offering a more complete and parsimonious organization of what characterizes the development of trust. Nevertheless, the four dimensions still acquired new nuances stemming from the interviews.

After outlining the preliminary version, the items and their dimensions were submitted to "face and content validation" according to the recommendations of Netemeyer et al. [16]. Some items were excluded, added, modified in order to better fit the definitions of the dimensions. The face validity suggested that a seven-point (0-strongly disagree to 6-strongly agree) scale with labels was the most suitable kind for teachers to respond during their working hours. Finally, the Trust Scale was applied in person to 559 teachers from thirty schools of the Campinas municipal system de Ensino Fundamental ( $1^{\text {st }}$ to $9^{\text {th }}$ grade).

The following part of this article will be focused on explaining the compound of tests used for statistical validation and at last it will present the retained items that composed the Final Scale. Afterwards we will discuss these quantitative findings coupled with some qualitative data brought from the ethnographic research conducted in two schools of the municipal educational system: school A belongs to the group of schools with the highest levels of trust, and school B was reported to have the lowest level of trust - both according to the Likert scale and confirmed by field observations.

\section{Statistical Validation and the Final Scale}

For the statistical validation, the technique of confirmatory factorial analysis of suggestive order was used [17] (with the software SmartPLS 2.0, because there was a factorial model determined by the expert judges. For the evaluation of the quality of the adjustments were considered the Cornbach's alpha test, the composite reliability, the mean variances extracted and The Pearson's coefficient of determination. Student's t test values were also analyzed to confirm the correlation relationships between the observed variables and the constructs, and the regression coefficients [18]. Finally, the discriminant validity, the evaluation of the path coefficients and the effect size $\mathrm{f}^{2}$ and the accuracy of the constructs or predictive relevance $\left(\mathrm{Q}^{2}\right)$ were evaluated [19]. After Small adjustments, the values obtained indicated that the criteria of statistical validity were very satisfactory.

As results, we had good adjustment levels. Table 1 shows the values of the adjustment tests and in the bottom line the reference values. The constructs were called G (teachers-management team); PR (teachersteachers), PA (teachers-parents) and S (teachersMunicipal Department of Education).

Table 1. Goodness of fit adjustment model

\begin{tabular}{|c|c|c|c|c|}
\hline & AVE & $\begin{array}{l}\text { Composite } \\
\text { Reliability }\end{array}$ & $\begin{array}{c}\text { R } \\
\text { Square }\end{array}$ & $\begin{array}{c}\text { Cronbachs } \\
\text { Alpha }\end{array}$ \\
\hline G & .529 & .951 & 0,737 & 0,945 \\
\hline PA & .543 & .913 & 0,407 & 0,893 \\
\hline PR & .514 & 0,927 & 0,373 & 0,913 \\
\hline $\mathbf{S}$ & .523 & 0,923 & .549 & 0,908 \\
\hline $\begin{array}{l}\text { reference } \\
\text { values }\end{array}$ & $>.50$ & $>.70$ & $\begin{array}{c}\text { Big } \\
=.27 ; \\
\text { Median } \\
=.13 ; \\
\text { Small } \\
=.02 \\
{[20]}\end{array}$ & $>.70$ \\
\hline
\end{tabular}

We also calculate the discriminant validity of the adjusted model. The table 2 shows these values.

Table 2. Discriminant validity - Fornell and Larcker criteria [21]

\begin{tabular}{|c|c|c|c|c|}
\hline & G & PA & PR & S \\
\hline G & 0,727 & & & \\
\hline PA & 0,379 & 0,737 & & \\
\hline PR & 0,345 & 0,267 & 0,717 & \\
\hline S & 0,470 & 0,416 & 0,309 & 0,723 \\
\hline
\end{tabular}

Note: On the main diagonal are the square root values of AVEs. These should be larger than the correlations with the corresponding latent variables [21]

Analyzing table 2, it can be seen that the adjusted model has discriminant validity and, in sequence, we can be given, evaluating if the correlations and regression coefficients are valid. This is accomplished with bootstrapping method. Thus, we evaluate the values of Student's T tests are greater than 1.96 [19]. In the case of the adjusted model all values met this requirement.

Finally, the effect size $\left(f^{2}\right)$ and the predictive validity $\left(\mathrm{Q}^{2}\right)$ of the model we analyzed. $\mathrm{f}^{2}$ is the indicator that shows whether the various constructs are important for the model (values of 0.02 are considered small, 0.15 are mean, 0.35 large) [20] and $\mathrm{Q}^{2}$ indicates whether there is accuracy or precision in the model $\left(Q^{2}>0\right)$ [18]. Table 3 shows the values obtained: 
Table 3. Predictive Validity $\left(\mathrm{Q}^{2}\right)$ and Effect Size $\left(\mathrm{f}^{2}\right)$

\begin{tabular}{|c|c|c|}
\hline & $\mathbf{Q}^{2}$ & $\mathbf{f}^{\mathbf{2}}$ \\
\hline $\mathbf{G}$ & 0,385 & 0,478 \\
\hline $\mathbf{P A}$ & 0,219 & 0,431 \\
\hline $\mathbf{P R}$ & 0,187 & 0,423 \\
\hline $\mathbf{S}$ & 0,286 & 0,432 \\
\hline
\end{tabular}

Note: for $\mathrm{f}^{2}$, values of 0.02 are considered small, 0.15 are mean, 0.35 large [20] and for $\mathrm{Q}^{2}>0$ [18]

We finally show the final structure of the Scale with the retained items which met very satisfactorily all the criteria of statistical validity.

\section{Table 4. Trust Scale}

\section{Construct 1. TEACHERS - PARENTS (PA)}

1. I can count on parents to do my job.

2. I feel respected by the parents of my students.

3. Parents in this school listen to what we say about their children education.

4. Parents have confidence in teachers' work.

5. Parents do their best to help their children learn.

6. Parents are interested in the school matters.

7. Teachers and parents in this school are partners in educating children.

8. Parents are close to their children's school life.

9. Parents in this school are always attending school meetings, parties and events.

Construct 2. TEACHERS - MANAGEMENT TEAM (G)

10. I can organize my class work autonomously.

11. I can count on principal's support to do my job.

12. Principal shares important information with teachers.

13. I feel alone in my daily work.

14. The management team is interested in the professional development of teachers.

15. I look for the pedagogical advisor when I need to talk about my practice.

16. I feel respected by the principal.

17. Teachers feel comfortable to express their opinion to the principal.

18. The principal does a good job in assuring adequate working conditions to our school.

19. Teachers feel their opinions and proposals are considered by the management team.

20. Principal has confidence in the expertise of the teachers.

21. Principal treats all students with respect.

22. I feel monitored at work.

23. The management team encourages the participation of all (staff, families, and students) in the formulation of the pedagogical project of the school.

24. The principal is committed to the well-being of all students.

25. The principal complies with the collective deals.

26. The pedagogical advisor and teachers are always talking about alternatives to help students who need it most.

27. Principal discourages collective decisionmaking.

Construct 3. TEACHERS - TEACHERS (PR)

28. Teachers can count on each other's help.

29. Teachers in this school respect each other.

30. Teachers like to learn from each other.

31. I feel comfortable to talk with my colleagues about the weaknesses of my work.

32. When a teacher has good ideas, he/she likes to share it with other teachers.

33. I have confidence in the expertise of my colleagues.

34. Teachers treat all students with respect.

35. Teachers in this school never give up on students, doing their best to help them all.

36. Teachers are committed to improving their own work.

37. Teachers hardly hear each other, because they do not value other teachers' knowledge.

38. We use to collectively evaluate our work.

39. Teachers in this school comply with collective deals.

Construct 4. TEACHERS - MUNICIPAL DEPARTMENT OF EDUCATION (S)

40. The supervisor knows the reality of our school. 41. The supervisor is always here when we call his/her help to address some problem.

42. The supervisor stands up for the needs of our school.

43. The Department of Education creates opportunities to hear teachers about educational matters.

44. Teachers' voices are considered by the Department of Education in decision-making processes.

45. The Department of Education fulfills its responsibility to ensure educational quality.

46. The Department of Education is committed to improving my professional development.

47. Regarding to infrastructure, the Department of Education provides our school with good working conditions.

48. The Department of Education ensures good working conditions in terms of providing the school with full professional staff.

49. In terms of wage/working journey, teachers of the municipal public system have good working conditions. 
50. I am satisfied with the performance of the municipal government in the educational field.

Note: Translated from Portuguese

\section{Discussing findings}

The axis factor analysis confirmed that all constructs are consistently related to each other and are relevant components of a single phenomenon called Trust, comprising both interpersonal and institutional trust. It allowed us to affirm that teachers' trust in the Municipal Department of Education is intrinsically related to teachers' trust in the school actors, highlighting the need for future researches on this topic to pay closer attention to how relationships at the school-level are affected by their external connections with the public authority.

The axis factor analysis also confirmed that the fifty remaining items are relevant elements of the phenomenon. It means that the development of trust also hinges on how teachers perceive opportunities to participate in decisions that affect their own lives and their students' lives, both in the school and the system levels. It became evident especially in their relations with the management team and the Department of Education, as suggested by the items 23, 27, 43 and 44. This observation calls for a broader definition of "respect" which is capable of including the collective construction of negotiated aims and conditions of schooling.

The descriptive analysis ${ }^{\text {iii }}$ reported that the lowest level of trust is in the Municipal Department of Education followed by the teachers-parents relationship.

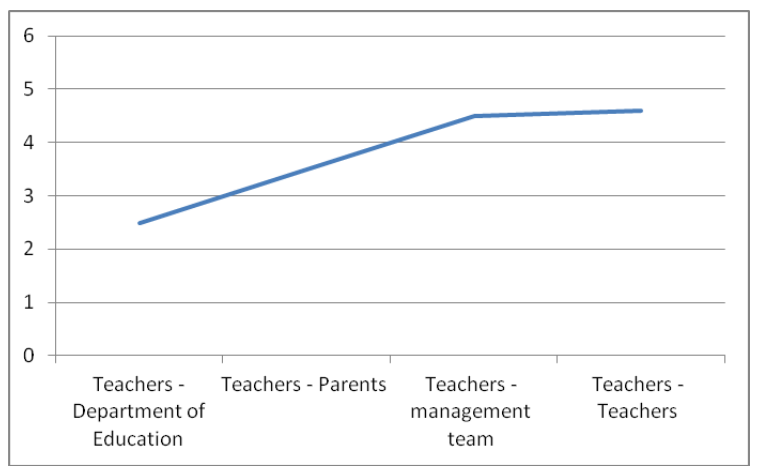

Figure 1. Levels of trust in each relational setting

In the first case, more than fifty percent of the respondents disagree that the public authority provides the schools with adequate infrastructure and full professional staff; the same pattern of disagreement was observed when teachers were asked if the Department of Education listen to them and consider their voices in the decision-making processes. Out of these findings it is possible to conclude that institutional and interpersonal trust is influenced by the extent to which the public authority is capable of fulfilling its responsibilities in terms of ensuring adequate working conditions, and also by the extent to which its structures are perceived to be opened to social participation.

Regarding the teachers-parents relationship, the low level of trust is especially telling and may bring about different explanations. In this case trust seems to be influenced by the "informal evaluation" teachers make with respect to parents and students which is inherently pervaded by social class assumptions. According to Freitas [7], "informal evaluation" is the process through which teachers evaluate students' behaviors and attitudes based on their own cultural capital and social class position, which plays a crucial role in determining students progression over the educational system.

It is possible to bring this concept to analyze the relationship between teachers and parents. In the school B (characterized by the lowest level of trust), parents are often "informally evaluated" as being "deficient", uninterested, feckless. Parents are rarely invited to school social events and parties. They are most expected to attend school either to become aware of their children's behavior and learning or to be "taught" and "disciplined" by teachers and the management team. Hence, teachers' lack of trust in parents can be explained by the fact that parents are always far away from reaching teacher's expectations which tend to be formulated in terms of social class prejudgements.

It raises some further questions. Hoy and Moran highlight how expectations - which offer the basis for trust - are shaped over time out of multiple social exchanges within the trustor group. Then, in order to increase trust, should parents just comply with the expectations shared by teachers within teachers group?

An alternative answer would be that they need to participate on the formulation of what is expected of them. This track of analysis was brought from some researches that investigated the consequences of the deployment of social capital theory in educational policies as an attempt to tackle social exclusion. Gewirtz et al [22] analyze specifically the Education Action Zones (EAZ) policy introduced by the New Labour government in the UK whose purpose was to raise educational achievement by building the intrafamily and home-school social capital of families identified as socially excluded. Examples of initiatives developed by the EAZs were the psychotherapeutic approaches for parents such as improving parenting skills and addressing family stress, and the family learning schemes designed to 
give parents the opportunity to learn specific skills which would better equip them as educators of their children. Although some of these initiatives have been positively experienced by individual parents, it failed to involve a significant number of parents besides not being able to engage participants in decision-making and to develop their capacity for collective political action. The authors argue that one of the reasons for this failure was the blind premise underpinning the establishment of the schemes, according to which working-class families were deemed to be "deficient", bereft of social networks, not valuing education and lacking inclination to actively engage with the education system. As a result of such negative judgments, the schemes tended to neglect the interests, concerns and perspectives of those who they were designed to help. Hence it was the the lack of recognition of people's values and choices that undermined the success of the practices concerned with challenging social exclusion. By recognition the authors mean

'being responsive to the full range of values and ways of life of people. Recognition is not just about inclusion in other people's agendas. Rather, it is about valuing whatever it is that is important to people and ensuring that policy agendas reflect and do not deny the breadth and depth of people's experiences and perspectives' [22]

How does it help us to offer an alternative answer to the need of achieving higher levels of trust between teachers and parents? Although trust has been traditionally conceived as one's compliance to the other's expectations, the previous considerations on the concept of recognition - coupled with the principle of communicative action embedded in the Participatory Institutional Evaluation Policy - lead us to think that the most suitable way of fostering trust is through an open dialogue whereby people from diverse and unequal backgrounds encounter each other and have their needs, capacities and voices recognized. These multiple social exchanges among the different groups and individuals then form the basis out of which shared expectations emerge and are constantly negotiated.

This framework helps us to explain the low levels of trust reported in School B where students and parents are barely listened to and are heavily blamed for their "underachievement". These deficit assumptions seen to reflect in the fact that student's productions rarely are published on the walls or posted on any communication channel. In this school, it was more usual to hear about what students do not master and about their shortcomings than to hear teachers praising and recognizing them for what they produce and who they are.
A very different situation was observed in the School A which belongs to the group with the highest levels of trust. Teachers created a wide range of opportunities and channels - such as school journals, a facebook page, the school's walls whereby they proudly share with other teachers, students and parents what their students produce in the classes and throughout the diverse projects carried out in this school. One of them, the "Africanitie(S)", is especially powerful in the way it positively affirms race identities that have been traditionally marginalized in the Brazilian society. Another characteristic that worth mentioning is that most of the teachers value the history of the surrounding community - a history of struggle for the right of having a land to live - and take it into account to elaborate their curricular activities.

Bearing such field observations in mind, it becomes evident that we are talking about a specific kind of educational quality - which is far beyond proficiency outcomes - and the possible ways it can be connected to the emergence of trust. Based on these small-scale field observations it is possible to state that trust seems to be crucial to account for the capacity of schools to engage in a collective institutional evaluation that leads to a broader acknowledgement of the aims of schooling.

The relation between academic attainment and trust has not been analyzed in this research. However, if we take a quick look at the IDEB $^{\text {iv }}$ scores of School A in comparison to School B, actually we will find that the school with higher level of trust - in which teachers work seems to be guided by the principles of social justice - is the one whose scores have been consistently lower over the years if compared to the scores of School B. This is at odds with what would be expected by the theory that found vivid positive correlations between trust and academic achievement [1] [5].

We do not intent to answer in this article the several questions raised by these brief observations, let alone come to a conclusion on the correlations among these data based only on a simple comparison between two schools. We also cannot lose sight of the fact that there are obviously many other variables affecting school outcomes such as the social contexts pervading schooling. Nevertheless, gathering these data into a small-scale analysis may allow us to acknowledge the limitations of judging schools through the lens of only one paramount measure of quality. It also entails that we have to pay closer attention to other meanings of quality that schools may be developing and to the way 'trust' may be a valuable asset to enact this broader development. 


\section{Conclusions}

In this article we showed that the existing literature sets out the concept of trust as a relational or organizational resource that leads to 'organizational effectiveness' and 'orientation towards innovation' through strengthening cooperation in the school-level. We also recognize the importance of trust to foster collective work, but especially because it enables democratic modes of regulation to flourish as an alternative to vertical accountability reforms. The existing literature also advocates that 'control was a dominant policy model of the past' whereas collective trust 'needs to be the policy framework of the future'. However, it seems that trust has been assigned with the role of enabling external reforms to be smoothly implemented rather than empowering local actors to reflect critically on educational aims.

In this sense, our perspective also aims at strengthening commitments and responsibilities of the various actors in order to achieve educational quality; but we try to go beyond by advocating that they need to be recognized as participants who influence decisions regarding their own lives and their students'. Therefore the concept of 'trust' can be more useful if conceived beyond its connection with the aims of adaptability and organizational effectiveness. We argue that relational and institutional trust must be shaped especially in the light of the aims of "social justice" [9]. Schools with high levels of trust are those where students feel culturally recognized and respected? Are those in which people feel active and equitable participants in society? Are those in which one contributes responsibly to, and benefits from, its external communities? We believe these questions carry the potential to set out new challenges for future researches on this field.

\section{References}

[1] P. B. Forsyth; C. M. Adams; W. K. Hoy. Collective trust: why schools can't improve wihout it. Teachers College Press, New York, 2011.

[2] M. Tschannen-Moran; W. K. Hoy. "Trust in schools: a conceptual and empirical analysis". Journal of Educational Administration, 36 (4), 1997, p. 334-352.

[3] W. K. Hoy; M. Tschannen-Moran, "Five Faces of Trust: an empirical confirmation in urban elementary schools". Journal of School Leadership, 1999, p. 184-208.

[4] C. J. Tarter, J. R. Bliss, W. K. Hoy, "School characteristics and faculty trust in secondary schools". Educational Administration Quarterly, 25 (3), 1989, p. 294-308.
[5] A. Bryk, B. Schneider, Trust in Schools: a Core Resource for Improvement. Russell Sage Foundation, New York, 2002.

[6] P. Sahlberg, "The fourth way of Finland". J. Educ. Change, 12 (2), 2011, p.173-185

[7] L. C. Freitas, "Os reformadores empresariais da educação: da desmoralização do magistério à destruição do sistema público de Educação". Educação \& Sociedade. 33 (119), 2012, p. 379-404.

[8] D. Ravitch, The death and life of the great American school system: how testing and choice are undermining education. Basic Books, New York, 2011.

[9] S. Gewirtz, The managerial school: post-welfarism and social justice in education. Routledge, London, 2002.

[10] M..R..L. Sordi; E. Souza, A avaliação institucional como instância mediadora da qualidade da escola pública: a Rede Municipal de Educação de Campinas como espaço de aprendizagem. Millenium, Campinas-SP, 2009.

[11] G.W.S. Campos. Um método para análise e cogestão de coletivos. Hucitec, São Paulo, 2007.

[12] A. Honneth, "Educação e esfera pública democrática: um capítulo negligenciado da filosofia política". Civitas, 13 (3), 2013, 544-562.

[13] J. Habermas, Teoria de la acción comunicativa: Complementos y estúdios previos. Catedra, Madri, 1994.

[14] M.R.L. Sordi, "Processos de responsabilização alternativos: a luta por concepções de qualidade na/da escola pública". XVI ENDIPE - Encontro Nacional de Didática e Práticas de Ensino, Brasil, 2012.

[15] L. Bardin. Análise de conteúdo. Editora 70, Lisboa, 2004.

[16] R. G. NETEMEYER, et al. Scaling Procedures: issues and applications. Sage Publications, California, 2003.

[17] D. Rindskopf; T. Rose, "Some Theory and Applications of Confirmatory Second-Order Factor Analysis", Multivariate Behavioral Research, 23 (1), 5167, 1998, DOI: 10.1207 / s15327906mbr2301_3.

[18] J.F. Hair; G.T.M. Hult; C. M. Ringle; M. A. Sarstedt, Primer on Partial Least Squares Structural Equation Modeling (PLS-SEM). Thousand Oaks, CA: Sage, 2014.

[19] C. M. Ringle; D. Silva; D. Bido, "Structural Equation Modeling with the Smartpls". Brazilian Journal Of Marketing, 13 (2), 2014, p.56-73.

[20] J. COHEN, Statistical Power Analysis for the Behavioral Sciences. Psychology Press, New York, 1998. 
[21] C. Fornell; D.F. Larker, "Evaluation structural equation models with unobservable variables and measurement error: algebra and statistics". Journal of Marketing Research. 18 (3), 1981, p.382-388.

[22] S. Gewirtz, et. al. "The deployment of social capital theory in educational policy and provision: the case of Education Action Zones in England". British Educational Research Journal. 31 (6), 2005, p. 651-673.

\section{Acknowledgments}

The data and partial discussions of this article stem from an ongoing $\mathrm{PhD}$ research conducted by Sara Badra de Oliveira at the State University of Campinas, which is funded by FAPESP - Fundação de Amparo à Pesquisa do Estado de São Paulo, Brazil.

\footnotetext{
i As an example of a "ground" difference, the first framework develops the concept of "collective trust" whereas the second is based on "relational trust". Although the former researchers argue that their approach is sociological and criticize the second for their so-called "psychological perspective", we believe that in terms of operationalizing the concept both provide significant sociological contributions to understanding organizational phenomena and organizational outcomes.

ii According to Bryk and Schneider, trust is more likely to develop inside homogeneous settings especially in terms of ethnicity. In addition, the ideal setting would be small schools, intentionally built by the principal's decision power on the matter of hiring and firing teachers and by the voluntary membership of parents who choose where to enroll their children and of teachers who choose where they prefer to work. A place like this would facilitate the emergency of trust insofar as it eliminates potential conflicts and tensions.

iii The descriptive analysis was conducted in the software SPSS 15.0. At first the means of the answers were obtained for each item, providing the values used to calculate the means for each construct. It allowed us to come with the following values representing the levels of trusts: teachersmunicipal department of education: 2, 49; teachersparents: 3,5; teachers management team: 4,5; teachersteachers: 4,6 as displayed in the Figure 1.

iv Índice de Desenvolvimento da Educação Básica (IDEB) was created in 2007 to measure the quality of education throughout the national education system. It comprises two measures: pass rates and the average proficiency of students in Portuguese and Maths.
} 